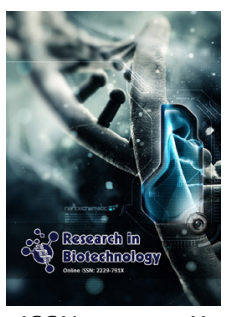

ISSN: $2231-539 X$

\title{
Knowledge, attitude and practice of self medication among the staff-members of Charotar University of Science and Technology
}

\author{
Jalpa Suthar', Jeet Munjani², Carissa Mendes², Tatvee Mendha², \\ Bansari Patel ${ }^{2}$ \\ 'Department of Pharmacology, Ramanbhai Patel College of Pharmacy, Charusat, Changa, Dist- Anand, Gujarat \\ State- 388421 India, ${ }^{2}$ Ramanbhai Patel College of Pharmacy, Charusat, Changa, Gujarat, India
}

\begin{abstract}
Self-medication raises its occurrence in many situations in our everyday lives, which is an inappropriate and harmful practice. A research framework was conducted to evaluate the awareness, attitude and practice of self-medication among the CHARUSAT University staff members. Among the staff members, a pre-validated questionnaire was circulated. Using Microsoft Excel, information was gathered and evaluated and the results were represented as numbers and percentages. Total 136 staff-members voluntarily took part in the study. We found that, source of information of the drugs used for self-medication were "previous prescription $(77.7 \%)$ " and source of drugs was "medical store (78.8\%)". Only (34.3\%) staff-members accepted the fact that they always visited a qualified practitioner whenever they got sick. Most of the staff-members took self-medication for headache $(73.5 \%)$ followed by cough, cold, sore throat $(73.5 \%)$ and fever $(56.6 \%)$. Out of total 136 staff-members most of them took Analgesics (61.8\%) as self-medication followed by lozenges $(66.2 \%)$. For almost $66.9 \%$ of university staff members, self-medication was common. They provided a reason that "no need to visit a doctor for minor illnesses". $73.5 \%$ of the population has taken cough and cold preparations as self-medication.
\end{abstract}

Dr. Jalpa Suthar

E-mail: jalpasuthar.ph@

charusat.ac.in

KEYWORDS: Self-medication, Questionnaire, Knowledge, Attitude, Practice

\section{INTRODUCTION}

Self Medication is known as the common practice of using medication such as over-the-counter (OTC) medicines for minor ailments without a registered medical practitioner's consultation. In developed and developing countries, it is a part of self-care [1][2]. However, in developed countries, self-medication cases are on an increased scale as people live there think it is the first line of treatment for minor health issues such as headaches, vomiting, cough and cold, fever [3]. Other factors, consisting of prior experience in the treatment of similar diseases, knowledge of medications and their use, incessant advertisement and lack of access to trained health professionals [1], may also be responsible for such practice [1].

Many factors have been found to play a role in leading to self-medication practice among staff members, such as easy drug availability, drug manufacturers advertisement, prior encounters with symptoms or disease [4][5].Self-medication can save money and lives if used wisely, but if used irrationally, it can raise the risk of adverse incidents, bacterial infection, hypersensitivity, drug tolerance, signs of drug withdrawal and masking disease that can delay proper diagnosis[6].In the proper use of non-prescription medications, self-medication used safely can play a crucial role, improving protection and reducing undesirable drug effects [7]. Families, acquaintances, pharmacists, previous prescription medication, articles, drug advertisements and the internet are the most common sources of self-medication [8].

Among the CHARUSAT campus students, a research with a similar aim was performed. The current study among the staff members of the CHARUSAT campus was suggested, taking into account the results of the previous study [9].

Copyright: $\odot$ The authors. This article is open access and licensed under the terms of the Creative Commons Attribution License (http://creativecommons.org/licenses/by/4.0/) which permits unrestricted, use, distribution and reproduction in any medium, or format for any purpose, even commercially provided the work is properly cited. Attribution - You must give appropriate credit, provide a link to the license, and indicate if changes were made. 


\section{METHOD}

\section{Subject Enrolment Details}

As shown in Figure 1, all of CHARUSAT's current departments / institutes were involved in data collection. The number shown in the figure was the voluntary contribution of staff members from different departments / institutes.

\section{Study Site}

The study was carried out among the staff members of the Charotar University of Science and Technology (CHARUSAT), Changa.

\section{Study Design}

It is a questionnaire-based, cross-sectional study design. From the previous study [3][7], a questionnaire on self-medication was taken. For data collection, the English language was considered appropriate.

\section{Data Collection Process}

By contacting the staff members of the CHARUSAT campus, a questionnaire-based survey was carried out. The nature of the research and the context of the questionnaire were briefly clarified to the staff members. Both participants were presented with details concerning the questionnaire on self-medication behaviors. Verbal consent was obtained and research participation was entirely voluntary. First questions were asked about the habit of self-medication practice (yes or no) and if the answer is "YES" then subsequent leading questions were included about age, gender, education status, source of information, awareness of effective self-medication practice, types of drugs used for selfmedication and diseases leading to self-medication.

\section{Data Analysis}

Data were presented as number counts and percentages. Descriptive analysis was used to represent the data. Microsoft Excel was used for analysis of data.

\section{RESULTS}

There was a total of 136 staff members, of whom $83(61 \%)$ were men and $53(39 \%)$ were women. The mean age was found to be $43.5 \pm 2$ years, varying between 21 and 65 years. A total of $99(72.8 \%)$ staff members have taken self-medication, while the remaining $37(27.2 \%)$ staff members have never taken self-medication to date.

\section{Knowledge}

Most common reasons for taking self-medication was like "there was no need to visit doctor for minor illness 91 (66.9\%)" followed by "self-medication provided quick relief 61 (44.85\%)", "it was time saving $37(27.20 \%)$ ", and "there was ease and convenience in taking self-medication 42 (30.88\%)”. (see Table 1)

Figure 2 represented the sources of the drugs used for selfmedication. Majority of participants $73(77.7 \%)$ answered "previous prescriptions" followed by 78 (78.8\%) "medical store”.

The most common reason for not taking self-medication were such as "there was lack of knowledge about medicines $17(41.5 \%)$ ", "risk of adverse effects 15 (36.6\%)", "risk of using wrong drugs 16 (39\%), risk of misdiagnosing 9 (22\%).(See Table2)

\section{Attitude}

In our study, we found that out of 136 staff-members only 59 (56.2\%) staff-members accepted the fact that "they sometimes visited a qualified medical practitioner whenever they fell ill", while 36 (34.3\%) staff-members said that "they always visited" and 10 (9.5\%) staff-members "visited rarely" as depicted in Figure 3.

\section{Practice}

Out of 136 staff-members, most of the staff-members $100(73.5 \%)$ took self-medication for headache followed by

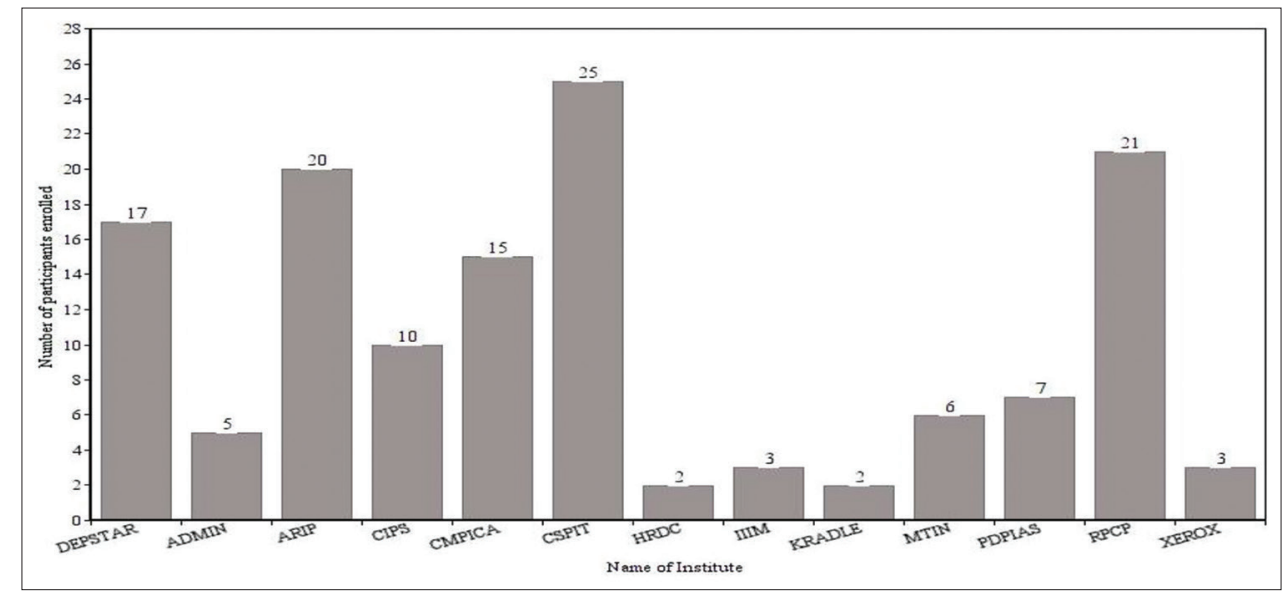

Figure 1: CHARUSAT's departments / institutes for data collection. 
Suthar, et al.

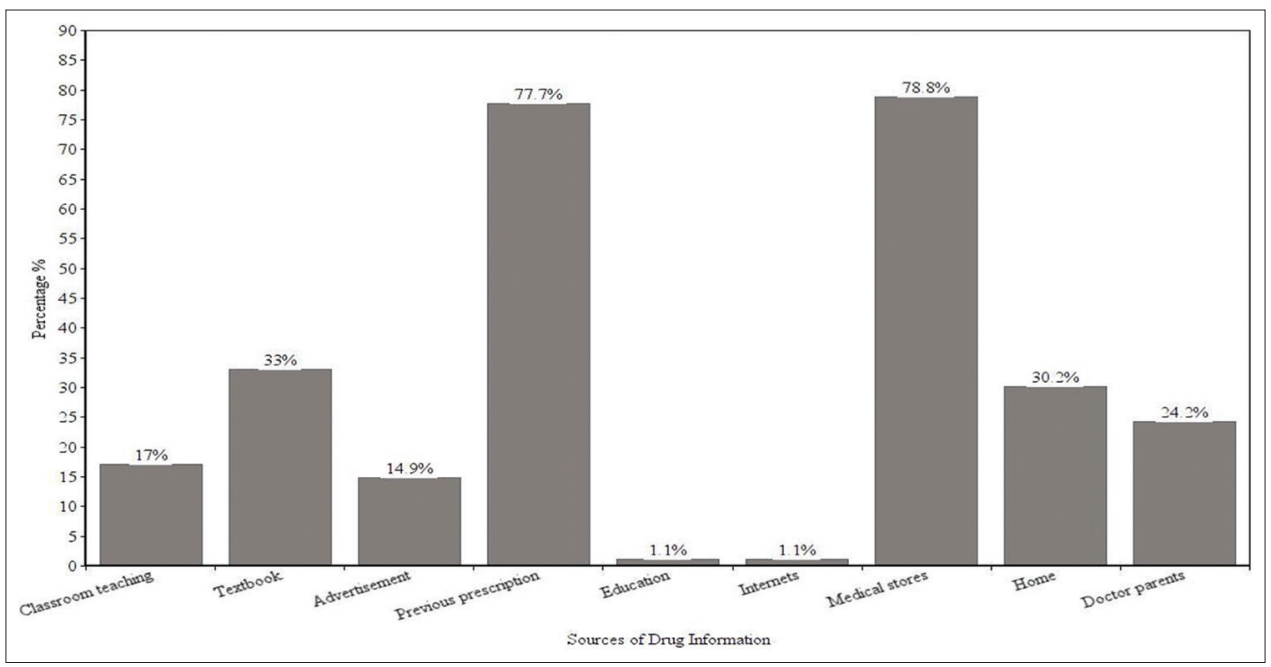

Figure 2: Sources of drug Information for Self-medication

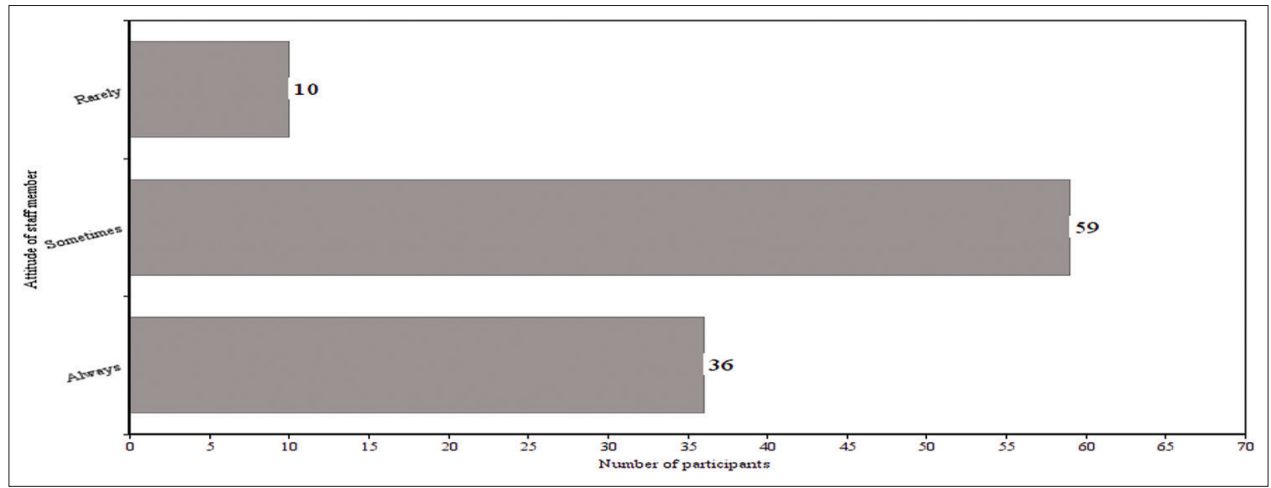

Figure 3: Attitude of Staff-members while visiting Hospital

Table 1: Reasons for Self-medication

\begin{tabular}{llcc}
\hline Sr. No. & Reason for Self-Medication & Numbers ( $\mathrm{n})$ & Percentage (\%) \\
\hline 1 & $\begin{array}{l}\text { Confidence on your } \\
\text { knowledge about medicine }\end{array}$ & 43 & 31.61 \\
& & 42 & 30.88 \\
2 & Ease and convenience & 91 & 66.9 \\
3 & No need to visit doctor for & & \\
& minor illness & 61 & 44.85 \\
4 & Quick relief & 37 & 27.20 \\
5 & Time saving & 16 & 11.76 \\
6 & Economical & 8 & 5.88 \\
7 & Learning opportunities & 6 & 4.41 \\
8 & Crowd avoidance & & \\
\hline
\end{tabular}

cough, cold and sore throat 100 (73.5\%), and fever 77 (56.6\%). Out of 136 staff-members, most of the staff-members 84 (61.8\%) took analgesics as self-medication followed by cough and cold preparation 99 (66.2\%). (Figure 4 and Table 3)

\section{DISCUSSION}

Staff-members in CHARUSAT campus are doing selfmedication very often. In the present study, 136 staffmembers of the university were contacted and from that $72.8 \%$ staff-members answered "YES" in reference to self-medication. It indicates that the overall incidence of
Table 2: Reasons for not taking medication

No. Reason for not taking Self-Medication Numbers (n) Percentage (\%)

1 Lack of knowledge about medicines $\quad 17 \quad 41.1$

2 Risk of adverse effects $\quad 15 \quad 36.6$

3 Risk of using wrong drugs $\quad 16 \quad 39$

4 Risk of misdiagnosing $\quad 9 \quad 22$

5 Risk of drug dependence $\quad 7 \quad 17.1$

$\begin{array}{llll}6 & \text { Risk of using drugs wrongly } & 13 & 31.7\end{array}$

self-medication is high in our university, which is similar to previous studies [10-12].

In our study, male staff-members $(61 \%)$ were interested in taking self -medication most often as compared to Female staff-members (39\%). Reason for higher use of self-medication in male staff-members is negligence to visit hospital for minor illness.

\section{Knowledge}

In current study, most of the staff-members used selfmedication in favor that "there was no need to visit doctor for minor illness 91 (29.5\%)", "self-medication provided quick relief 61 (19.8\%)", "it was time saving 37 (12\%)", and "there was 


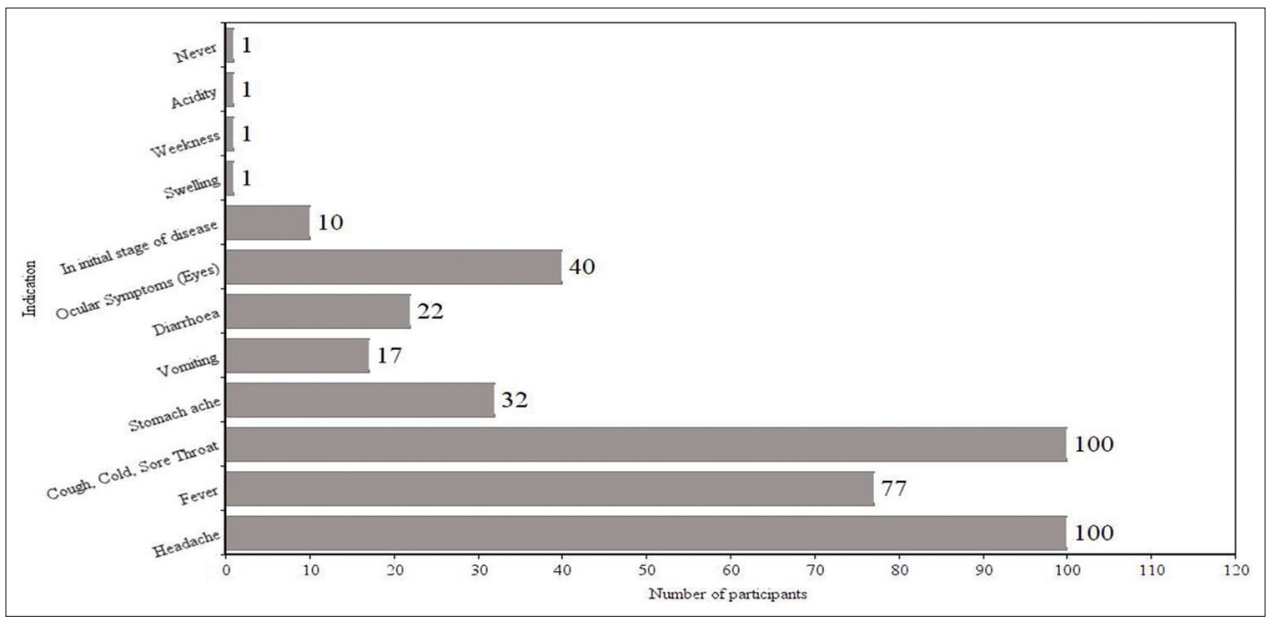

Figure 4: Indication for the use of Self medication

Table 3: Drugs used for Self-medication

\begin{tabular}{llcc}
\hline No. & Drugs used for Self-medication & Numbers (n) Percentage (\%) \\
\hline 1 & Analgesics (For Pain) & 84 & 61.8 \\
2 & Antibiotics (For Infection) & 46 & 33.8 \\
3 & Multivitamins (For Nutritional) & 49 & 36 \\
4 & Antiemetics (For Vomiting) & 26 & 19.1 \\
5 & Antispasmodics (For Abdominal Pain) & 18 & 13.2 \\
6 & Iron Preparation (For Anemic) & 14 & 10.3 \\
7 & Cough \& Cold Preparation & 90 & 66.2 \\
\hline
\end{tabular}

ease and convenience in taking self-medication 42 (13.6\%)". rest of the staff-members are not taking self-medication due to "lack of knowledge about medicines 17 (41.5\%)", "risk of adverse effect 15 (36.6\%)"," risk of using wrong drugs 16 (39\%)", "risk of misdiagnosis 9 (22\%)". Similar findings were observed [13][14].

In the present study, the majority of the staff-members used "previous prescription" as a source of information about drugs. However, other sources such as advertisement, textbooks and classroom teaching also influence self-medication knowledge in study. The findings clearly indicate that staff-members of the university avoid visiting doctors consequently for the same type of complaint and use previous prescriptions as a source of information. The World Health Organization (WHO) has also pointed out that responsible self-medication can help prevent and treat ailments that do not require medical consultation and provide a cheaper alternative for treating common illnesses [15]. However, it is also recognized that self-medication must be accompanied by appropriate health information.

This study highlights the different sources of information on drugs for self-medications such as medical store, home and doctor parents. We found that the majority of the staff-members referred "medical stores (78.8\%)" for self-medication. While home and doctor parents contributed less. In India, the majority of the population consult community pharmacists for their minor illnesses and avoid visiting doctors for the same. So, the similar findings were seen in the study [10] [16].

\section{Attitude}

The attitude of CHARUSAT campus staff-members towards the hospital visit was found (34.3\%) always, (9.4\%) rarely and $(56.2 \%)$ visited a medical practitioner sometimes. Similar findings were reported previously [17].

\section{Practice}

In the present study, majority of the staff-members did selfmedication for the indication of "headache (73.5\%)" followed by "cough, cold and sore throat (73.5\%)" and fever (56.6\%).

The self-medication may be found rational when the situation is not serious and the complaint is well evident [11][18] like headache and cough, cold and sore throat. The use of Over-theCounter (OTC) medicine may be justified only if the safety is high and drug related side effects are less. Similar findings on practice and indication for self-medication are seen in studies [11,13].

The Analgesics have been reported to be the most commonly used group of drugs $[19,20]$. So, in our study we also found similar results. The use of Antibiotics is (40\%) in the present study. The finding is opposite to the previous study [13][21].

\section{CONCLUSION}

The self-medication prevalence among the staff was high. A total of $72,8 \%$ of staff on campus took their own medicine. The staff describes how "the doctor should not have to be visited for mild illness." Cough and cold preparation treatments were taken as self-medication by 73.5 percent of the population. Awareness and self-medication attitude of staff is good. However, while taking medicine, special precautions are required.

\section{REFERENCES}

1. Musa Y, Awosan KJ, Ibrahim MT, Abdullahi Z, Jafaar MM, Peter G, Anthony $\mathrm{O}$, Isah BA. Knowledge and practice of self-medication among undergraduate students of Usmanu Danfodiyo University, Sokoto. Ann. Int. Med. Den. Res. 2016;2(1):83. 
Suthar, et al.

2. Khamis S, Sheqer H, Arsoy G. Knowledge, Attitude and Practice of Self-medication among Pharmacy Students in North Cyprus. Journal of Pharmaceutical Research International. 2019 Aug 31:1-0.

3. Gyawali S, Shankar PR, Poudel PP, Saha A. Knowledge, attitude and practice of self-medication among basic science undergraduate medical students in a medical school in western Nepal. Journal of clinical and diagnostic research: JCDR. 2015 Dec;9(12):FC17.

4. Bhatia MK, Ripudaman S, Akashdeep S, BL B. Knowledge, Attitude and Practice of self medication among undergraduate medical students of Punjab. The Journal of Medical Research. 2017;3(3):151-4.

5. World Health Organization. Report of the WHO Expert Committee on National Drug Policies. Geneva: World Health Organization; 1995. https://www.who.int/medicines/library/dap/who-dap-95-9/whp-dap95.9.shtml.

6. Jain S, Malvi R, Purviya JK. Concept of self medication: A review. Int J Pharm Biol Arch. 2011;2(3):831-6.

7. Sankdia RK, Agrawal M, Rekha PB, Kothari N. A questionnaire based study regarding the knowledge, attitude and practice of selfmedication among second year undergraduate medical students. International Journal of Pharmacology and Clinical Sciences. 2017;6(1).

8. Faiz A, Seema M, Deep I, Shaista A. Self-medication practices and attitude among dental students of a metro city of North India. Int J Biomed Res 2018;4:118-21.

9. Jalpa Suthar, Patel Shrina P, Solanki Riddhi N. Knowledge, Attitude and Practice of Self-Medication Among the Students of Private university. Asian Journal of Pharmaceutical and Research. 2020; Vol 13(8): 104-107.

10. Klemenc-Ketis Z, Hladnik Z, Kersnik J. Self-medication among healthcare and non-healthcare students at University of Ljubljana, Slovenia. Medical Principles and practice. 2010;19(5):395-401.

11. Mumtaz Y, Jahangeer SA, Mujtaba T, Zafar S, Adnan S. Self-medication among university students of Karachi. J Liaquat Univ Med Health Sci. 2011;10:102-5.
12. Raut P, Vamsi D, Rao BV. Evaluation of the knowledge, attitude and practice of self-medication among second year B.Sc nursing students. J Drug Deliv Sci Technol. 2014;4:150-3.

13. James H, Handu SS, AI Khaja KA, Otoom S, Sequeira RP. Evaluation of the knowledge, attitude and practice of self-medication among first-year medical students. Medical principles and practice. $2006 ; 15(4): 270-5$.

14. Montgomery AJ, Bradley C, Rochfort A, Panagopoulou E. A review of self-medication in physicians and medical students. Occupational medicine. 2011 Oct 1;61(7):490-7.

15. Kafle KK, Policy-WHO M, World Health Organization. Self-medication and its impact on essential drugs schemes in Nepal-a sociocultura research project.

16. Kulkarni P, Ajmera A, Gadekar S, Garg A, Mahajan A, Kulkarni P. Global scenario of self medication: A review of literature. Indian journal of commerce and management studies. 2018;9(1):99-107.

17. Ali SE, Ibrahim MI, Palaian S. Medication storage and self-medication behaviour amongst female students in Malaysia. Pharmacy Practice. 2010 Dec 20;8(4):226-32.

18. Susheela F, Goruntla N, Bhupalam PK, Veerabhadrappa KV, Sahithi B Ishrar SM. Assessment of knowledge, attitude, and practice toward responsible self-medication among students of pharmacy colleges located in Anantapur district, Andhra Pradesh, India. Journal of education and health promotion. 2018;7.

19. Hughes CM, McElnay JC, Fleming GF. Benefits and risks of self medication. Drug safety. 2001 Dec 1;24(14):1027-37.

20. Aljinović-Vučić V, Trkulja V, Lacković Z. Content of home pharmacies and self-medication practices in households of pharmacy and medica students in Zagreb, Croatia: findings in 2001 with a reference to 1977. Croatian Medical Journal. 2005 Feb 1;46(1).

21. Hailemichael W, Sisay M, Mengistu G. Assessment of knowledge, attitude, and practice of self-medication among Harar health sciences college students, Harar, Eastern Ethiopia. J Drug Deliv Ther 2016;6:31-6 